\title{
Percutaneous management of metastatic osseous disease
}

\author{
Steven Yevich ${ }^{1}$, Lambros Tselikas $^{2}$, Alexis Kelekis ${ }^{3}$, Dimitrios Filippiadis $^{3}$, Thierry de Baere ${ }^{2}$, Frederic Deschamps ${ }^{2}$ \\ ${ }^{1}$ Department of Interventional Radiology, Division of Diagnostic Imaging, The University of Texas MD Anderson Cancer Center, Houston, Texas, \\ USA; ${ }^{2}$ Department of Interventional Radiology, Gustave Roussy Cancer Campus Grand Paris, Villejuif, France; ${ }^{3} 2$ nd Department of Radiology, \\ General University Hospital "ATTIKON”, National and Kapodistrian University of Athens, Athens, Greece \\ Contributions: (I) Conception and design: S Yevich; (II) Administrative support: S Yevich; (III) Provision of study materials or patients: S Yevich; (IV) \\ Collection and assembly of data: S Yevich; (V) Data analysis and interpretation: S Yevich; (VI) Manuscript writing: All authors; (VII) Final approval of \\ manuscript: All authors. \\ Correspondence to: Steven Yevich, MD, MPH. MD Anderson Cancer Center, 1400 Pressler St, FCT14.6024, Houston, Texas 77030, USA. \\ Email: syevich@mdanderson.org.
}

\begin{abstract}
Metastases to the bone represent the third most common site of metastatic disease. More than $50 \%$ of patients with metastatic cancer will develop bone metastases. Associated morbidity is related to local tumor progression that destroys bone to result in pain, pathologic fracture, hypercalcemia, and neurologic deficits. Depending on the tumor biology, systemic chemotherapy or radiation therapy may not provide complete local control and may not adequately relieve associated pain. While surgical intervention may be beneficial in many patients, surgical options may also provide incomplete locoregional cure or palliation, and moreover may require extensive healing that can delay systemic therapy. Interventional oncology treatments can provide appealing alternative therapies for osseous metastases. These minimally-invasive therapies can augment existing conventional treatments and even provide a viable option for patients that have exhausted, or are not suitable candidates, for conventional treatments. Interventional oncology treatments are applied for either pain palliation, local tumor control, or both. The goals of treatment can include tumor remission or cure, as well as improved quality of life and mobility. An effective and durable interventional oncology treatment requires a tailored approach that considers the high variability in disease presentation. Osseous metastases may present throughout the skeleton, with low to high vascularity, and undulant to rapidly aggressive tumor biology. This article reviews the main percutaneous treatment for osseous metastases that include embolization, thermal ablation, vertebral augmentation, cementoplasty, and fixation by internal cemented screw (FICS).
\end{abstract}

Keywords: Bone; malignancy; metastasis; fixation; osseous; ablation

Submitted Aug 15, 2019. Accepted for publication Sep 30, 2019.

doi: $10.21037 /$ cco.2019.10.02

View this article at: http://dx.doi.org/10.21037/cco.2019.10.02

\section{Introduction}

Osseous metastases represent the third most common site of metastatic disease following the liver and lung, with reported incidence in greater than $50 \%$ of cancer patients with metastatic disease (1-3). The clinical presentation and sequela of osseous metastases can result in substantial morbidity related to either pain or locoregional tumor growth (4-6). Conventional treatment options of systemic chemotherapy, surgical resection, and radiation therapy may be limited by side-effects, risks, or associated comorbidities. In these cases, alternative minimally-invasive treatment options may be pursued.

Several effective interventional oncology treatment options are available including embolization, ablation, vertebral augmentation, cementoplasty, and percutaneous screw fixation (7). Treatments are often individualized for pain palliation, local tumor control, prevention of future skeletal-related events, or a combination of the preceding. 

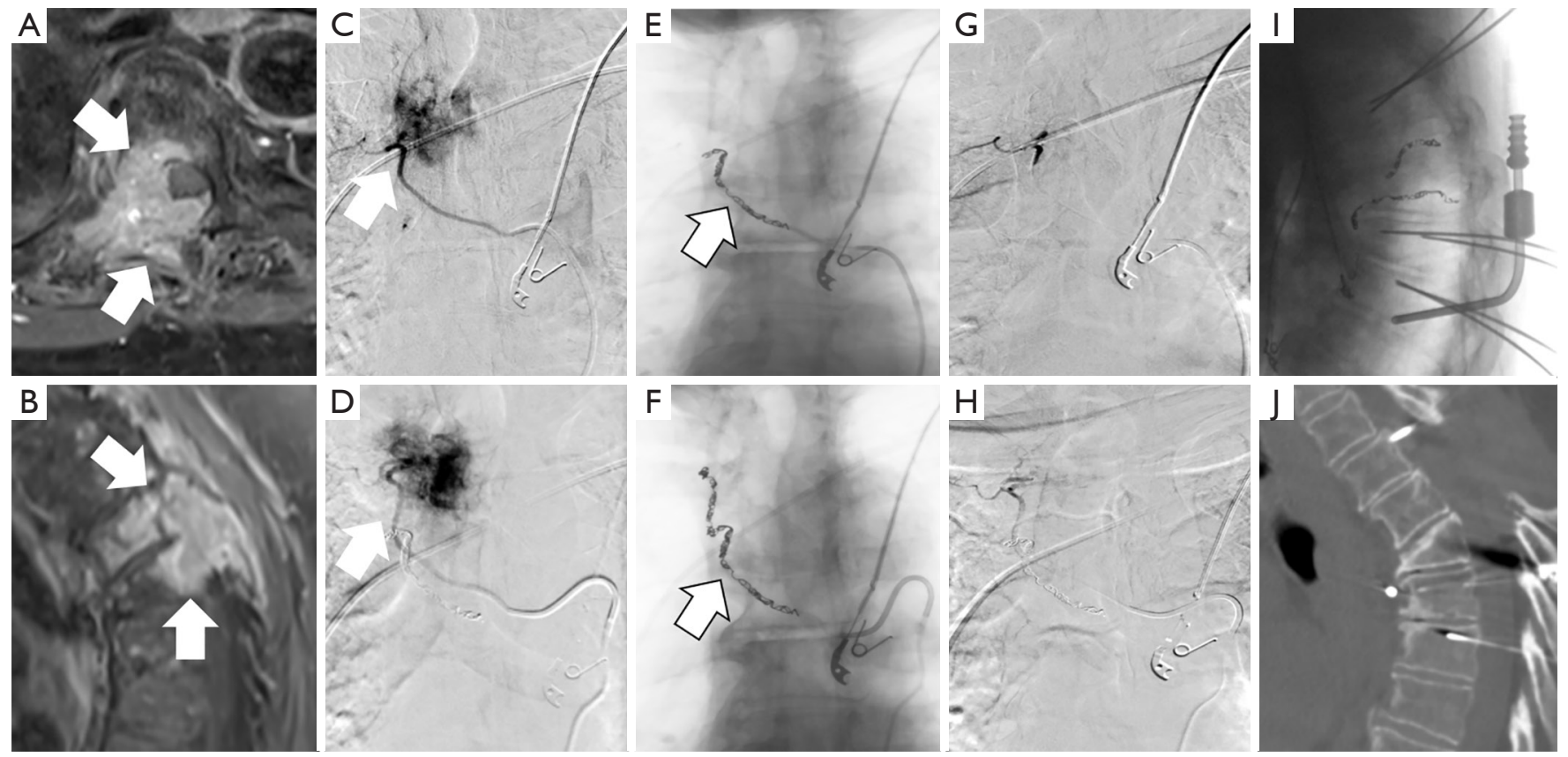

Figure 1 An 81-year-old woman with renal cell carcinoma metastasis to the right lateral aspect of the T4 vertebrae with tumor extension into the spinal canal (arrows; A,B). Tumor embolization performed as a pre-surgical measure to minimize intra-operative bleeding during resection and laminectomy. Selective angiograms demonstrated prominent vascular supply from the right T4 and T5 arteries (arrows; C,D respectively), which were embolized to stasis with $400 \mathrm{~nm}$ particles and then packed with coils [arrows; (E,F) identifies coils for both arteries, respectively]. Post-embolization angiograms of the T4 and T5 arteries demonstrate absence of previously seen tumor blush (G,H respectively). The patient underwent upper thoracic laminectomy and tumor resection the following morning [surgical intraoperative images $(\mathrm{I}, \mathrm{J})]$.

The approach is tailored to overcome the unique treatment challenges of the metastasis to provide cure or remission when possible and improve the patient's quality of life and mobility, decreased opioid dependence, and lower overall healthcare costs (8-14).

Pain treatments for osseous metastases, in particular, require astute understanding of the underlying etiology of pain so as to be able to select the most suited minimallyinvasive interventional oncology (IO) treatment. Pain may result from tumor growth that results in periosteal tumorassociated inflammation, tumor mass effect on adjacent soft tissues, cortical bone destruction that causes structural instability or fracture, or erosion of tendon attachments (15). In addition to the pain attributable directly to the cancer, pain may result indirectly due to cancer-related osteoporosis from immobility or from cancer-associated pain and altered bone metabolism related to chemotherapy, hormone therapy, steroid therapy, and radiotherapy.

This article reviews the current interventional oncology treatment options for osseous metastases. Supportive literature will be discussed for each treatment option.

\section{Embolization}

Endovascular occlusion of tumor arterial blood supply provides a pain palliative treatment option that is effective when metastatic osseous tumors demonstrate increased vascularity compared to surrounding soft tissues. The technical aspects of embolization vary widely based on tumor vascularity, location, and operator experience. All embolic materials may be used including embolic beads, gelatin sponge, coils, ethanol, glue or ethylene vinyl alcohol copolymer (Onyx, ev3, Irvine, CA, USA) (16). The size of the tumor feeding vessels, presence of arterio-venous shunts, and ability to exclude muscular arterial supply often guide the selection of embolic material injected during treatment.

Embolization may be used as a pre-surgical adjunct or applied independently for pain palliation $(8-11,15,16)$. The indication to perform a pre-surgical embolization (Figure 1) is to reduce intraoperative bleeding, thus decreasing surgical risk and improving surgical resection outcome by improving intra-operative tumor visualization (16-19). Alternatively, embolization may be applied directly and independently as a 

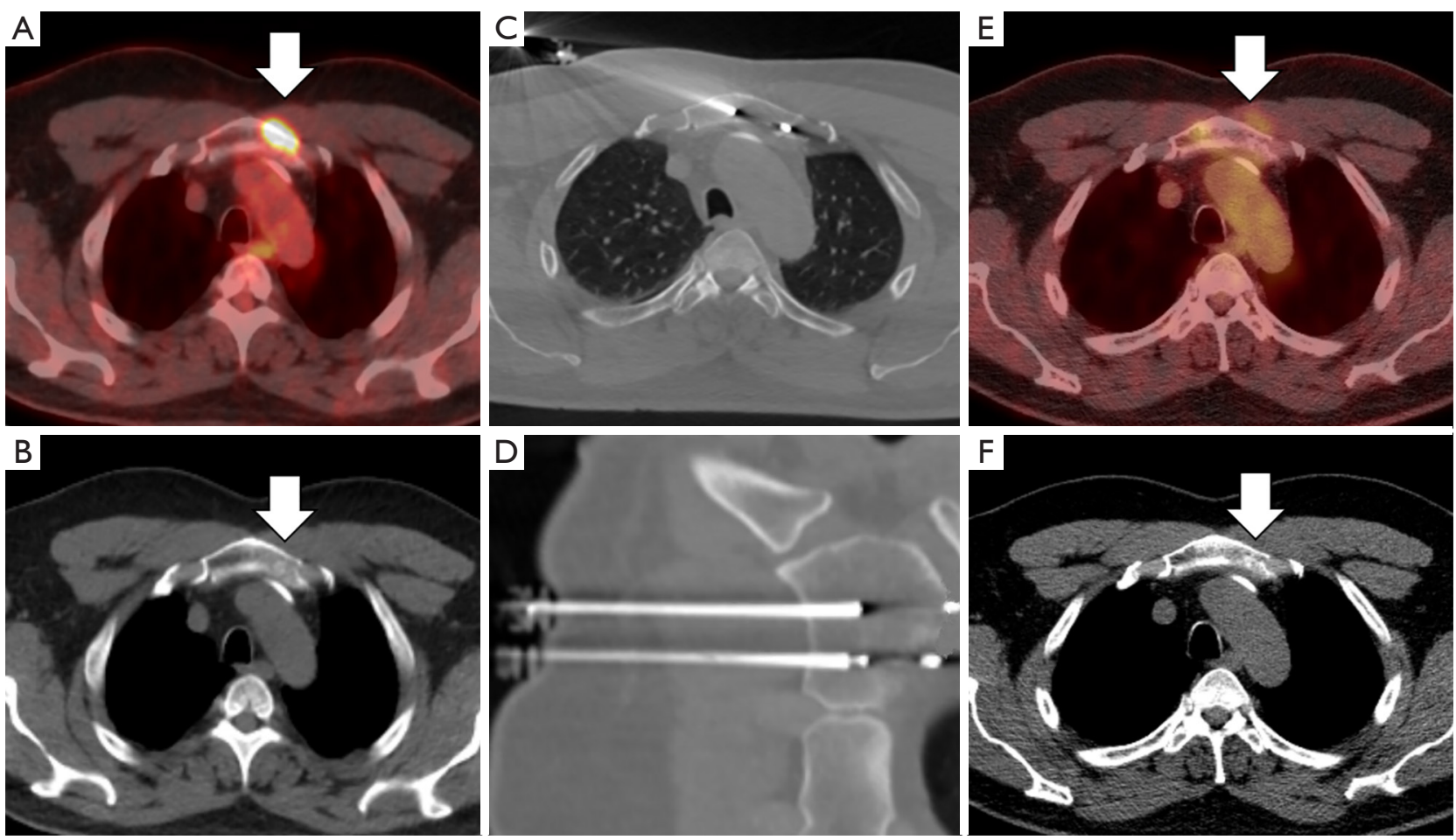

Figure 2 A 60-year-old man with metastatic adenocarcinoma of the colon. PET/CT demonstrates FDG-avid lesion (arrow; A) in the left manubrium with corresponding mixed sclerotic-lytic lesion on CT (arrow; B). Treatment by cryoablation using two probes for local tumor control (C,D). Follow up PET/CT performed 2 months later confirms treatment response with absence of FDG-avidity (arrow; E) and unchanged CT appearance (arrow; F).

pain palliative procedure. Mechanisms for pain relief include impedance of locoregional osteolysis, downregulation of cytokine-mediated tumor-associated inflammation, and reduction of tumor volume to relieve periosteal stretching and tumor mass effect on surrounding tissues $(20,21)$.

Multiple retrospective reviews report the tumoral and pain response to embolization. As this treatment is most effective for vascular tumors, literature is most prominent for the treatment of renal cell carcinoma (RCC) and thyroid metastases. Several small case series report mild to marked pain relief within 2 weeks that lasts a mean of $1-6$ months, with decreased opioid dependence, and decrease in tumor progression $(22,23)$. A large retrospective review of 309 embolization procedures for painful bone metastases from renal, thyroid, breast, and lung cancer in 243 patients reported greater than $50 \%$ pain reduction in $97 \%$ of patients and decreased analgesic use for a mean duration of 8.1 months (24).

\section{Thermal ablation}

Thermal ablation may be applied for both local tumor control and pain palliation. The treatment relies on the placement of special needle probes that deliver a controlled energy to a finite tumor volume to cause irreversible tumor cellular death (25). The most common technologies used in the bone are radiofrequency ablation and cryoablation. Ablation modality selection is dependent on tumor size, tumor vascularity, tumor location in relation to adjacent critical structures, and operator experience.

The pain palliation effects from ablation are multifactorial and include destruction of sensory fibers that supply the periosteum, decompression of tumor volume, eradication of cytokine producing tumor cells, decreased tumor perfusion, and inhibition of osteoclast activity (26-28). A durable pain response with approximately $50 \%$ pain level decrease can be expected regardless of the modality employed (7). Palliative response has also been reported in patients who have already been treated with radiation therapy, suggesting a complementary effect $(29,30)$.

Local tumor control may also be achieved through percutaneous ablation (Figure 2), with improved results in lesions that measure less than $3 \mathrm{~cm}$ in greatest dimension 

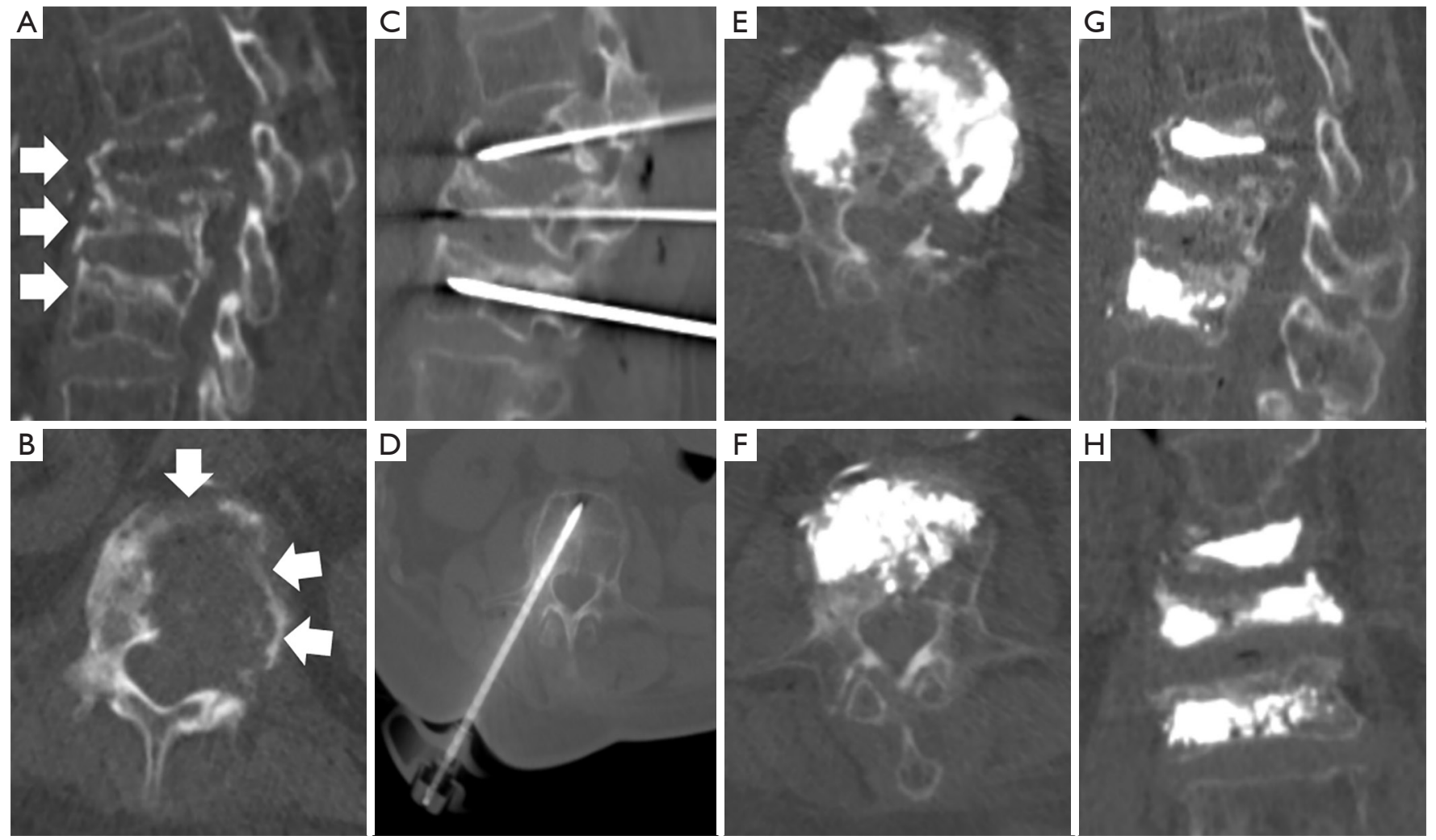

Figure 3 A 74-year-old woman with multiple myeloma developed pathologic compression fractures at T12, L1, and L2 vertebral bodies (arrows; A,B, sagittal and axial projections respectively). Compression fractures associated with mechanical pain despite opioids, steroids, and radiation therapy. Pain is characterized as 8 out of 10 , worse with weight bearing activities including sitting, and limits her ability to stand without support from a walker. Treatment with CT guided vertebroplasty at all three levels with unipedicular approach (C,D, sagittal \& axial projections respectively) with distribution of PMMA across midline in the anterior half of the vertebral bodies [post-procedure CT in axial (E,F), sagittal (G), and coronal (H) projections]. PMMA, typically polymethyl methacrylate.

$(31,32)$. Radiofrequency ablation and cryoablation have documented local control rates reported between 67-97\% in studies with at least 12 -month follow up (33). For example, a study that evaluated treatment outcome with either radiofrequency ablation (74 lesions) or cryoablation (48 lesions) for multiple primary cancer types reported a one year local control rate of $67 \%$ after median follow up of 22.8 months (26). Ablation of larger lesions can also confer local control if curative margins can be safely obtained; however, reports are limited to case reports or small case series.

\section{Vertebral augmentation}

Vertebral augmentation encompasses the treatments of vertebroplasty and kyphoplasty, and has been well documented as a pain palliative treatment for osseous metastases to the spine $(34,35)$. Small caliber needles are inserted into the vertebral body and a bone filler [typically polymethyl methacrylate (PMMA)] is subsequently injected under careful image guidance by CT or fluoroscopy (Figure 3).

The pain palliative effects result from the restoration of structural integrity as the physical properties of the injected bone cement (typically PMMA) provide resistance to the axial compressive forces experienced during weight bearing activities. A multicenter randomized controlled trial of 134 patients reported significant pain relief in patients who underwent kyphoplasty compared to the non-surgical treatment group (36). While vertebral augmentation is indicated for painful fractures from both pathology and osteoporosis etiology, the durability was reported to be greater for pathologic fractures (37). In a multicenter prospective study, vertebroplasty performed for metastatic 

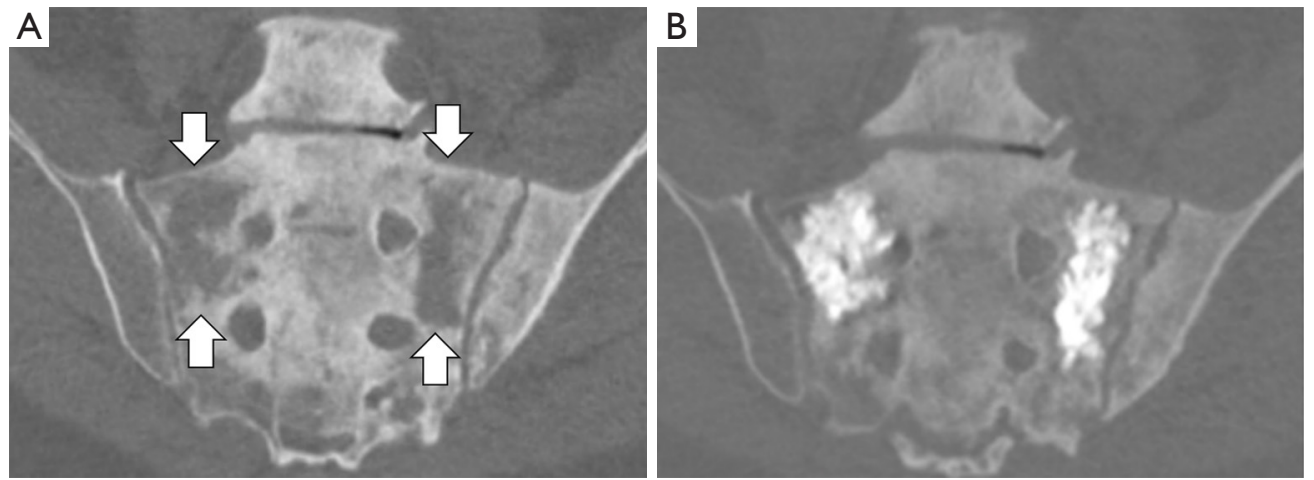

Figure 4 A 70-year-old man with metastatic prostate cancer to the osseous structures, with a mixed lytic and sclerotic metastates in the sacrum. Lytic lesions (arrows; A) resulted in mechanical pain in the lower back with prolonged standing and transitions from a sitting to standing position. Percutaneous cementoplasty performed with injection of PMMA (polymethyl methacrylate) to the bilateral sacral lytic regions (B) resulted in relief of the mechanical pain.

compression fractures in 4,547 patients $(13,437$ vertebral levels) provided significant pain relief with average pain score decrease from 8.3 to 1.7 (38).

The application of vertebroplasty versus kyphoplasty is at the discretion of the operator and often depends upon degree of vertebral body compression and presence of tumor extension through the posterior vertebral body into the epidural space. Satisfactory pain palliation may be achieved regardless of the method applied. A meta-analysis that reviewed the clinical outcomes from 2000 to 2014 (111 studies with 4,235 patients) of both vertebroplasty and kyphoplasty for pathologic compression fractures showed a significant pain reduction, reduction of analgesic use, and improvement in disability scores (39).

\section{Cementoplasty}

Cementoplasty, also known as osteoplasty, applies the image-guided techniques of vertebral augmentation to osseous structures outside of the spine (Figure 4) $(40,41)$. The percutaneous injection of PMMA can provide direct palliative relief by consolidation of weight-bearing bone subjected to axial compression forces (42). Mean pain scores can be significantly decreased by this outpatient procedure with long term durability, regardless of primary tumor type $(43,44)$. In addition, the technique can be applied as a preventative measure for impending pathological fractures $(41,45)$. While cementoplasty can provide substantial palliative benefit, the procedure is less effective in locations subjected to torque stresses or when tumor invades a joint or tendon insertion (46).

\section{Fixation by internal cemented screw (FICS)}

Fixation by internal cement screw is a technique that stabilizes an osseous metastasis through the advancement of metallic screws across a skeletal tumor defect, followed by cement consolidation (Figure 5) $(47,48)$. The treatment is performed for pain palliation or as a preventative measure for impending pathologic fracture (49). The addition of metallic screws to cementoplasty confers a greater resistance to torque and tension stresses to complement the resistance of PMMA to axial forces $(45,47,48,50,51)$. This minimally-invasive procedure is performed under fluoroscopic or CT image guidance through a small $1-2 \mathrm{~cm}$ incision for each screw.

While the principles, tools, and equipment for internal fixation have been developed in surgical subspecialties, interventional oncologists have recently advanced this pain palliative procedure through the application of advanced image guidance techniques that include needle guidance navigation software and real-time tracking improves. The safety and efficacy of interventional oncology FICS techniques using both CT and fluoroscopic guidance have been reported for pelvic and proximal femoral pathologic fractures (52-57). A single center clinical review of 100 patients with greater than 1 year follow up reported significant improvement in numerical pain scale in $80 \%$ of patients and decreased opioid usage at 6 weeks follow up (58).

\section{Combination 10 treatments}

As the role of minimally-invasive treatments expands to address the highly variable presentation of osseous 

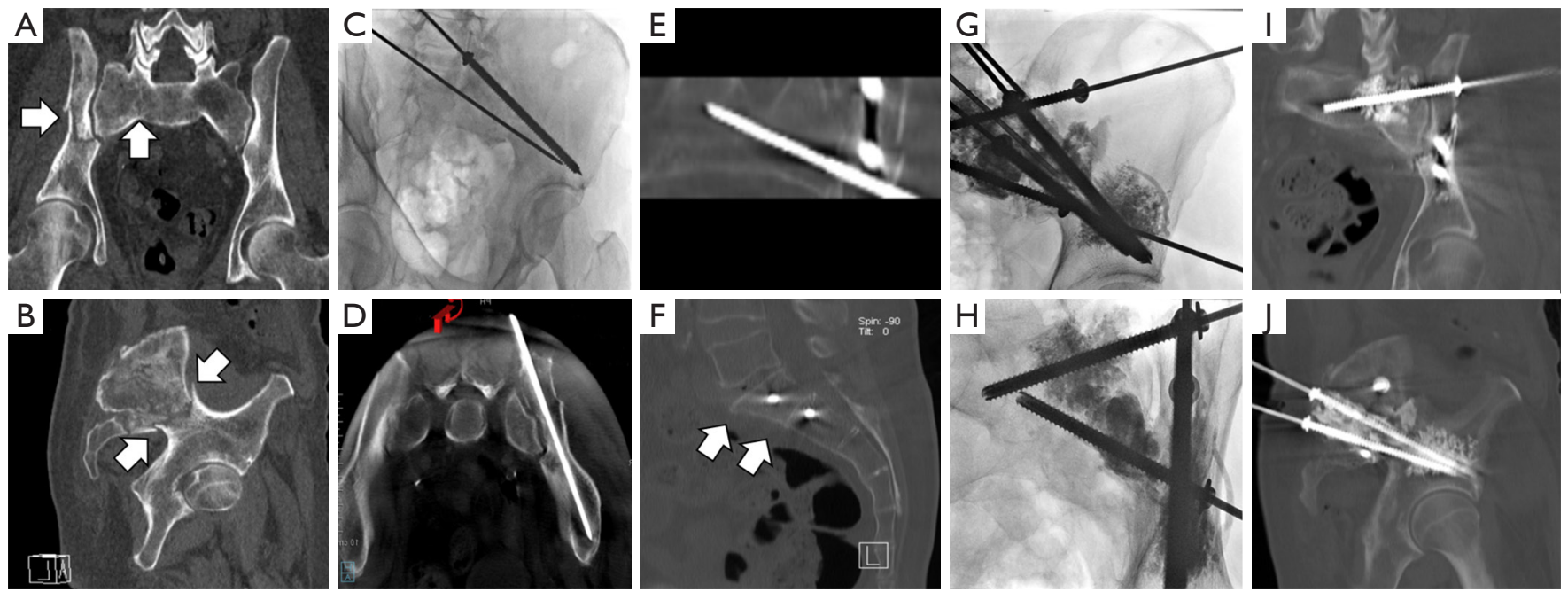

Figure 5 A 62-year-old man with metastatic melanoma to the right posterior iliac bone and right sacrum resulting in pathologic fractures [arrows; coronal oblique (A) and sagittal oblique (B) projections]. Fractures result in severe right pelvic pain with weight bearing, and necessitate the use of a walker. Fixation by internal cemented screw with placement of two cannulated fully threaded screws across the iliac fracture [intra-procedural images (C,D)] and two cannulated screws across the sacral fracture [intra-procedural images (E,F), arrows in image (F) identify two screw tips within the S1 and S2 vertebral bodies]. PMMA cement injection under both CT and fluoroscopic guidance $(\mathrm{G}, \mathrm{H})$. CT images before removal of Kirschner wires demonstrated satisfactory fixation of the two fractures, without significant cement leakage from the osseous margins (I,J). PMMA, typically polymethyl methacrylate.

metastases, creative solutions are being developed to improve locoregional tumor control and durability of pain palliation. Challenges to comprehensive IO treatment can be attributed to the combination of aggressive tumor biology, large tumor size, increased tumor vascularity, and tumor location adjacent to critical structure such as motor or sensory nerves. New procedural equipment are addressing these challenges. For example, several small case series have evaluated the feasibility of combining ablation with cementoplasty or vertebroplasty (Figure 6), although direct comparison of effectiveness between the combination therapy and individual therapies still requires evaluation (59-61).

In addition to new IO tools, recent imaging advances have improved needle guidance, enabled fusion capabilities, and potentiated the integration of multiple imaging modalities (62). For example, integrated CT-fluoroscopy equipment (hybrid units) couple the ability to provide highresolution multidetector CT image guidance with the realtime spatial capabilities of fluoroscopy image guidance in the same procedural suite. This hybrid equipment can provide the means to leverage both imaging modalities within the same procedural setting and facilitate the application of synergistic treatments and protective measures for osseous metastases that would otherwise prove technically challenging to treat (63). For example, a highly vascular metastasis that has eroded through a large portion of bone may be treated using a hybrid CT-fluoroscopy unit with sequential application of embolization, large volume percutaneous ablation, and percutaneous screw fixation in the same setting. The embolization provides pain palliation and decreases the bleeding risk for subsequent ablation and fixation. The ablation provides durable locoregional control and the FICS improves patient mobility and pain palliation. The feasibility to combine techniques for a comprehensive treatment presents a new and exciting frontier in the minimally-invasive treatment of osseous metastases.

\section{Conclusions}

Interventional oncology therapies to treat osseous metastases include tumor embolization, thermal ablation, vertebral augmentation, cementoplasty, and FICS. These minimally-invasive, image-guided treatments can provide locoregional control, pain palliation, or both. The highly variable disease presentation necessitates tailored and individualized approaches to each osseous metastasis with consideration of tumor biology, size, location, and vascularity. Recent advancements in IO imaging and tools have emerged to overcome these challenges and improve 

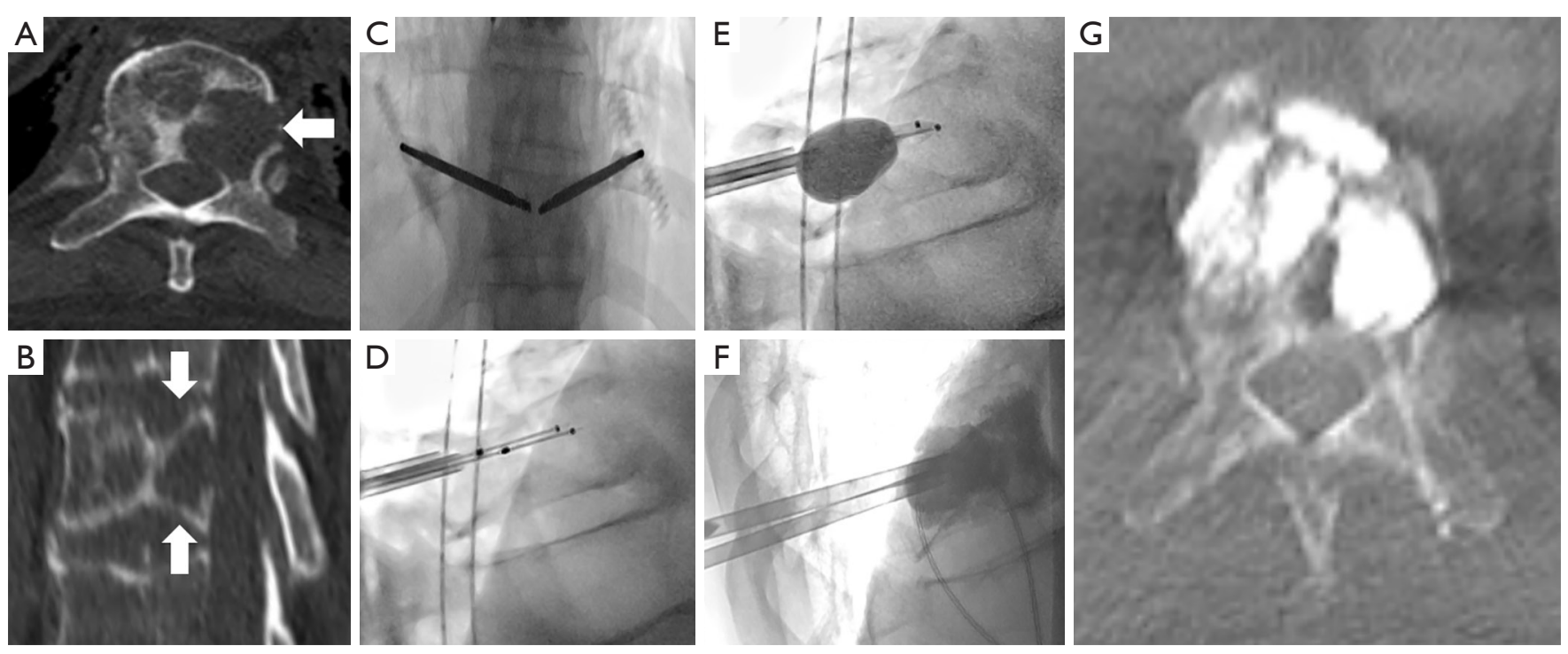

Figure 6 A 57-year-old woman with metastatic melanoma to the T10 vertebral body resulting in pathologic fracture (arrows; A,B) with significant positional and weight-bearing pain that limited mobility and activities of daily living. Given the pain presentation and the location of the lytic lesions along the posterior aspect of the vertebral body, the treatment access to the vertebral body was bipedicular (C), with radiofrequency ablation for pain palliation and local tumor control (D), and balloon kyphoplasty [(E) demonstrates balloon \& (F) demonstrates injection of PMMA cement]. Post-procedure CT demonstrates PMMA (polymethyl methacrylate) throughout the vertebral body $(\mathrm{G})$ without clinically significant leakage.

clinical outcomes.

\section{Acknowledgments}

None.

\section{Footnote}

Conflicts of Interest: The authors have no conflicts of interest to declare.

Ethical Statement: The authors are accountable for all aspects of the work in ensuring that questions related to the accuracy or integrity of any part of the work are appropriately investigated and resolved.

\section{References}

1. Coleman RE. Clinical features of metastatic bone disease and risk of skeletal morbidity. Clin Cancer Res 2006;12:6243s-6249s.

2. Roodman GD. Mechanisms of bone metastasis. N Engl J Med 2004;350:1655-64.

3. Li S, Peng Yi, Weinhandl E, et al. Estimated number of prevalent cases of metastatic bone disease in the US adult population. Clin Epidemiol 2012;4:87-93.

4. Rizzoli R, Body JJ, Brandi ML, et al. Cancer-associated bone disease. Osteoporos Int 2013;24: 2929-53.

5. Oster G, Lamerato L, Glass A, et al. Natural history of skeletal-related events in patients with breast, lung, or prostate cancer and metastases to bone; a 15-year study in two large US health systems. Support Care Cancer 2013;21:3279-86

6. Saad F, Lipton A, Cook R, et al. Pathologic fractures correlate with reduced survival in patients with malignant bone disease. Cancer 2007;110:1860-7.

7. Kurup AN, Callstrom MR. Expanding role of percutaneous ablative and consolidative treatments for musculoskeletal tumours. Clin Radiol 2017;72:645-56.

8. Tsuzuki S, Park SH, Eber MR, et al. Skeletal complications in cancer patients with bone metastases. Int J Urol 2016;23:825-32.

9. Hill T, D'Alessandro P, Murray K, et al. Prognostic factors following pathological fractures. ANZ J Surg 2015;85:159-63.

10. Weinfurt KP, Li Y, Castel LD, et al. The impact of skeletal-related events on health-related quality of life in patients with metastatic prostate cancer. Ann Oncol 
2002;13:180.

11. Sathiakumar N, Delzell E, Morrisey MA, et al. Mortality following bone metastasis and skeletal-related events among women with breast cancer: a population-based analysis of U.S. Medicare beneficiaries, 1999-2006. Breast Cancer Res Treat 2012;131:231-8.

12. Oefelein MG, Ricchiuti V, Conrad W, et al. Skeletal fractures negatively correlate with overall survival in men with prostate cancer. J Urol 2002;168:1005-7.

13. Lage MJ, Barber BL, Harrison DJ, et al. The cost of treating skeletal-related events in patients with prostate cancer. Am J Manag Care 2008;14:317-22.

14. Mundy GR. Mechanisms of bone metastasis. Cancer 1997;80:1546-56.

15. Figura N, Smith J, Yu HM. Mechanisms of, and Adjuvants for, Bone Pain. Hematol Oncol Clin North Am 2018;32:447-58.

16. Ozkan E, Gupta S. Embolization of spinal tumors: vascular anatomy, indications, and technique. Tech Vasc Interv Radiol 2011;14:129-40.

17. Rilling WS, Chen GW. Preoperative Embolization. Semin Intervent Radiol 2004;21:3-9.

18. Kobayashi K, Ozkan E, Tam A, et al. Preoperative embolization of spinal tumors: variables affecting intraoperative blood loss after embolization. Acta Radiol 2012;53:935-42.

19. Owen RJ. Embolization of musculoskeletal bone tumors. Semin Intervent Radiol 2010;27:111-23.

20. Chuang VP, Wallace S, Swanson D, et al. Arterial occlusion in the management of pain from metastatic renal carcinoma. Radiology 1979;133:611-4.

21. Barton PP, Waneck RE, Karnel FJ, et al. Embolization of bone metastases. J Vasc Interv Radiol 1996;7:81-8.

22. Forauer AR, Kent E, Cwikiel W, et al. Selective palliative transcatheter embolization of bony metastases from renal cell carcinoma. Acta Oncol 2007;46:1012-8.

23. Eustatia-Rutten CF, Romijn JA, Guijt MJ, et al. Outcome of palliative embolization of bone metastases in differentiated thyroid carcinoma. J Clin Endocrinol Metab 2003;88:3184-9.

24. Rossi G, Mavrogenis AF, Rimondi E, et al. Selective arterial embolisation for bone tumours: experience of 454 cases. Radiol Med 2011;116:793-808.

25. Ahmed M, Brace C, Lee F, et al. Principles of and advances in percutaneous ablation. Radiology 2011;258:351-69.

26. Deschamps F, Farouil G, de Baere T. Percutaneous ablation of bone tumors. Diagn Interv Imaging 2014;95:659-63.

27. Dupuy DE, Liu D, Hartfeil D, et al. Percutaneous radiofrequency ablation of painful osseous metastases: a multicenter American College of Radiology Imaging Network trial. Cancer 2010;116:989-97.

28. Tomasian A, Wallace A, Northrup B, et al. Spine cryoablation: pain palliation and local tumor control for vertebral metastases. Am J Neuroradiol 2016;37:189-95.

29. Callstrom MR, Charboneau JW, Goetz MP, et al. Painful metastases involving bone: feasibility of percutaneous CT- and US-guided radio-frequency ablation. Radiology 2002;224:87-97.

30. Di Staso M, Gravina GL, Zugaro L, et al. Treatment of solitary painful osseous metastases with radiotherapy, cryoablation or combined therapy: propensity matching analysis in 175 patients. PloS One 2015;10:e0129021.

31. McMenomy BP, Kurup AN, Johnson GB, et al. Percutaneous cryoablation of musculoskeletal oligometastatic disease for complete remission. J Vasc Interv Radiol 2013;24:207-13.

32. Deschamps F, Farouil G, Ternes $\mathrm{N}$ et al. Thermal ablation techniques: a curative treatment of bone metastases in selected patients? Eur Radiol 2014;24:1971-80.

33. Kurup AN, Morris JM, Callstrom MR. Ablation of musculoskeletal metastases. AJR Am J Roentgenol 2017;209:713-21.

34. Filippiadis DK, Marcia S, Masala S, et al. Percutaneous Vertebroplasty and Kyphoplasty: Current Status, New Developments and Old Controversies. CardioVasc Intervent Radiol 2017;40:1815-23.

35. Ruiz Santiago F, Santiago Chinchilla A, Guzmán Álvarez L, et al. Comparative review of vertebroplasty and kyphoplasty. World J Radiol 2014;6:329-43.

36. Berenson J, Pflugmacher R, Jarzem P, et al. Balloon kyphoplasty versus non-surgical fracture management for treatment of painful vertebral body compression fractures in patients with cancer: a multicenter, randomized controlled trial. Lancet Oncol 2011;12:225-35.

37. Gangi A, Guth S, Imbert JP, et al. Percutaneous vertebroplasty: indications, technique, and results. Radiographics 2003;23:e10.

38. Anselmetti GC, Marcia S, Saba L, et al. Percutaneous vertebroplasty: multi-centric results from EVEREST experience in large cohort of patients. Eur J Radiol 2012;81:4083-6.

39. Health Quality Ontario. Vertebral Augmentation Involving Vertebroplasty or Kyphoplasty for CancerRelated Vertebral Compression Fractures: A Systematic Review. Ont Health Technol Assess Ser 2016;16:1-202.

40. Anselmetti GC, Manca A, Ortega C, et al. Treatment of 
extraspinal painful bone metastases with percutaneous cementoplasty: a prospective study of 50 patients. Cardiovasc Intervent Radiol 2008;31:1165-73.

41. Deschamps F, De Baere T. Cementoplasty of bone metastases. Diagn Interv Imaging 2012;93:685-9.

42. Wang Z, Zhen Y, Wu C, et al. CT Fluoroscopy-guided Percutaneous Osteoplasty for the Treatment of Osteolytic Lung Cancer Bone Metastases to the Spine and Pelvis. J Vasc Interv Radiol 2012;23:1135-42.

43. Anselmetti GC. Osteoplasty: Percutaneous bone cement injection beyond the spine. Semin Intervent Radiol 2010;27:199-208.

44. Sun G, Jin P, Liu XW, et al. Cementoplasty for managing painful bone metastases outside the spine. Eur Radiol 2014;24:731-7.

45. Deschamps F, Farouil G, Hakime A, et al. Percutaneous stabilization of impending pathological fracture of the proximal femur. Cardiovasc Intervent Radiol 2012;35:1428-32.

46. Yevich S, Tselikas L, Gravel G, et al. Percutaneous cement injection for the palliative treatment of osseous metastases: A technical review. Semin Intervent Radiol 2018;35:268-80.

47. Deschamps F, de Baere T, Hakime A, et al. Percutaneous osteosynthesis in the pelvis in cancer patients. Eur Radiol 2016;26:1631-9.

48. Cazzato RL, Koch G, Buy X, et al. Percutaneous imageguided screw fixation of bone lesions in cancer patients: double-centre analysis of outcomes including local evolution of the treated focus. Cardiovasc Intervent Radiol 2016;39:1455-63.

49. Deschamps F, Yevich S, Gravel G, et al. Percutaneous fixation by internal cemented screw for the treatment of unstable osseous disease in cancer patients. Semin Intervent Radiol 2018;35:238-47.

50. Collinge CA, Crist BD. Combined Percutaneous Iliosacral Screw Fixation With Sacroplasty Using Resorbable Calcium Phosphate Cement for Osteoporotic Pelvic Fractures Requiring Surgery. J Orthop Trauma 2016;30:e217-22.

51. Tian QH, He CJ, Wu CG, et al. Comparison of Percutaneous Cementoplasty with and Without Interventional Internal Fixation for Impending Malignant Pathological Fracture of the Proximal Femur. Cardiovasc Intervent Radiol 2016;39:81-9.

52. Kelekis A, Lovblad KO, Mehdizade A, et al. Pelvic osteoplasty in osteolytic metastases: technical approach under fluoroscopic guidance and early clinical results. J Vasc Interv Radiol 2005;16:81-8.

53. Strobl FF, Haeussler SM, Paprottka PM, et al. Technical and clinical outcome of percutaneous CT fluoroscopy- guided screw placement in unstable injuries of the posterior pelvic ring. Skeletal Radiol 2014;43:1093-100.

54. Amoretti N, Huwart L, Hauger O, et al. Percutaneous screw fixation of acetabular roof fractures by radiologists under CT and fluoroscopy guidance. AJR Am J Roentgenol 2013;200:447-50.

55. Pusceddu C, Fancellu A, Ballicu N, et al. CT-guided percutaneous screw fixation plus cementoplasty in the treatment of painful bone metastases with fractures or a high risk of pathological fracture. Skeletal Radiol 2017;46:539-45.

56. Routt ML, Simonian PT, Grujic L. The retrograde medullary superior pubic ramus screw for the treatment of anterior pelvic ring disruptions: a new technique. J Orthop Trauma 1995;9:35-44.

57. Fischer S, Vogl TJ, Marzi I, et al. Percutaneous cannulated screw fixation of sacral fractures and sacroiliac joint disruptions with CT-controlled guidewires performed by interventionalists: single center experience in treating posterior pelvic instability. Eur J Radiol 2015;84:290-4.

58. Roux C, Tselikas L, Yevich S, et al. Fluoroscopy and conebeam CT-guided fixation by internal cemented screw for pathologic pelvic fractures. Radiology 2019;290:418-25.

59. Kam NM, Maingard J, Kok HK, et al. Combined vertebral augmentation and radiofrequency ablation in the management of spinal metastases: an update. Curr Treat Options Oncol 2017;18:74.

60. David E, Kaduri S, Yee A, et al. Initial single center experience: radiofrequence ablation assisted vertebroplasty and osteoplasty using a bipolar device in the palliation of bone metastases. Ann Palliat Med 2017;6:118-24.

61. Basile A, Giuliano G, Scuderi V, et al. Cementoplasty in the management of painful extraspinal bone metastases: our experience. Radiol Med 2008;113:1018-28.

62. Jones AK, Yevich S. Imaging techniques to aid IR treatment of musculoskeletal malignancy. Semin intervent Radiol 2019;36:49-62.

63. Yevich S, Odisio B, Sheth R, et al. Integrated CTfluorscopy equipment: Improving the interventional radiology approach and patient experience for treatment of musculoskeletal malignancies. Semin intervent Radiol 2018;35:229-37.

Cite this article as: Yevich S, Tselikas L, Kelekis A, Filippiadis D, de Baere T, Deschamps F. Percutaneous management of metastatic osseous disease. Chin Clin Oncol 2019;8(6):62. doi: 10.21037/cco.2019.10.02 